Disponível em

http://www.anpad.org.br/rac

RAC, Rio de Janeiro, v. 20, n. 5, art. 6, pp. 630-650, Set./Out. 2016

http://dx.doi.org/10.1590/1982-7849rac2016150292

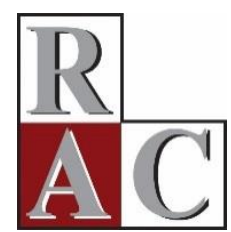

\title{
Fenomenografia e Valoração do Conhecimento nas Organizações: Diálogo entre Método e Fenômeno
}

\begin{abstract}
Phenomenography and the Valuing of Knowledge in Organizations: Dialog between Method and Phenomenon
\end{abstract}

Andréa Cherman ${ }^{1}$ Sandra Regina Rocha-Pinto ${ }^{1}$

Pontifícia Universidade Católica do Rio de Janeiro ${ }^{1}$

Artigo recebido em 29.10.2015. Última versão recebida em 04.04.2016. Aprovado em 09.04.2016. Publicado online em 03.08.2016. 


\title{
Resumo
}

A fenomenografia é um método de pesquisa qualitativa ainda pouco utilizado em estudos organizacionais. Visa a capturar as diversas concepções dos indivíduos acerca de um fenômeno, isto é, modos qualitativamente diferentes de experimentá-lo e concebê-lo (Marton, 1981; Marton \& Booth, 1997; Sandberg, 2000). O presente artigo conceitual objetivou revelar a experiência de pesquisa com o uso deste método, explicitando achados fortuitos emergentes não relatados na literatura com base em um estudo empírico realizado com profissionais de RH acerca da valoração do conhecimento no contexto do trabalho. $\mathrm{O}$ estudo revelou cinco concepções, que foram arranjadas de forma lógica, hierárquica, inclusiva e interdependente, conforme preconiza o método. Procedeu-se a um grupo de foco (Goldman \& McDonald, 1987) com participantes prototípicos, representativos de categorias distintas, para validar as categorias descritivas e aprofundar os achados fortuitos relativos ao método. O grupo de foco desvelou (a) a capacidade da fenomenografia em capturar o movimento bidirecional dos sujeitos pelas concepções ao experimentar o fenômeno; (b) o continuum ininterrupto entre as concepções; e (c) a trajetória dinâmica e flexível dos indivíduos pelas concepções no tempo e espaço, utilizando-as como modos de ação para guiar seus comportamentos diante dos diversos contextos.

Palavras-chave: método fenomenográfico; metodologia de pesquisa; entrevista em grupo; estudos organizacionais.

\begin{abstract}
Phenomenography is a little-known qualitative research methodology in organizational studies. It aims to capture the various conceptions individuals have about a phenomenon, that is, the different qualitative ways to experience and conceive of it (Marton, 1981; Marton \& Booth, 1997; Sandberg, 2000). This theoretical paper aimed to shed light on the research experience using the method, explaining unexpected emergent findings not reported in the literature, via an empirical study with HR professionals on valuing knowledge in the context of work. The research revealed five conceptions, which were arranged in a logical, hierarchical, comprehensive, and interdependent manner, as stated by the method. Then, a focus group (Goldman \& McDonald, 1987) with prototypical and representative participants of the categories was held in order to validate the descriptive categories and enhance understanding of the unexpected emergent findings. The serendipitous findings unveiled: (a) the capacity of phenomenography to capture subjects' two-way movement across conceptions in experiencing the phenomenon; (b) the uninterrupted continuum between the conceptions; and (c) the dynamic trajectory of individuals through conceptions in time and space, using them as modes of action to guide their behavior in relation to diverse contexts.
\end{abstract}

Key words: phenomenographic method; research methodology; group interview; organizational studies. 


\section{Introdução}

Os métodos qualitativos são relevantes para a compreensão dos fenômenos, em profundidade, ao buscar a perspectiva dos atores envolvidos, além de auxiliar no entendimento de como os indivíduos concebem a sua experiência com a realidade, dão significado e se comportam em relação a ela. A fenomenografia é um método qualitativo desenvolvido nos anos de 1970 pela Escola de Gotemburgo, por Marton e Säljö (1976), e que se fundamenta no princípio de que os indivíduos possuem diferentes concepções sobre algo ou sobre um fenômeno, baseados em suas experiências e vivências no mundo ou em aspectos do mundo. A conscientização sobre os diferentes conceitos, resultado das diversas percepções dos modos de experimentar o fenômeno, permite a sistematização das formas de pensamento em uma estrutura lógica, inclusiva e hierárquica. $\mathrm{O}$ entendimento de tal estrutura, por onde os indivíduos transitam no decorrer das repetidas experiências com o fenômeno, possibilita compreender como interpretam significantes aspectos da realidade (Marton, 1981; Marton \& Booth, 1997). Portanto, o propósito da pesquisa fenomenográfica é descrever e mapear as formas qualitativamente diferentes de experimentar o fenômeno (Marton \& Booth, 1997).

Assim, buscando explorar como os indivíduos percebem e significam os conhecimentos considerados de relevância, e que são, portanto, valorados no contexto do trabalho, foi conduzida uma pesquisa fenomenográfica (Marton, 1981; Marton \& Booth, 1997) com profissionais de Recursos Humanos (RH), a fim de analisar os diferentes modos (concepções) por meio dos quais os membros organizacionais percebiam e experimentavam a valoração do conhecimento no contexto do trabalho. Tratava-se de um estudo para contribuir com a área de Conhecimento Organizacional (CO) (Gherardi, 2000; Orlikowski, 2002; Patriotta, 2003). Do estudo empírico realizado, emergiram cinco concepções acerca da valoração do conhecimento no contexto do trabalho, retratando diferentes modos de se conceber o fenômeno nas organizações e de se comportar em relação a ele, em função do contexto sócioespaço-temporal (Akerlind, 2005a; Marton \& Booth, 1997) percebido naquele arranjo social (Latour, 2012).

Porém, ao se analisar a valoração do conhecimento a partir da percepção dos indivíduos, o estudo revelou achados fortuitos relacionados especificamente ao método fenomenográfico e não relatados na literatura: a capacidade do método fenomenográfico em capturar a dinâmica de movimento bidirecional dos sujeitos ao experimentar o fenômeno; o continuum ininterrupto entre as concepções; e a trajetória dinâmica e flexível dos indivíduos pelas concepções do fenômeno no tempo e espaço em relação ao contexto.

O estudo retratou, assim, a capacidade do método em capturar a fluidez de trânsito dos sujeitos pelas diferentes categorias descritivas, encontradas ao se estudar o fenômeno pela fenomenografia, até o nível de sua consciência focal. A pesquisa fenomenográfica demonstrou que os indivíduos se utilizam das diversas concepções como modos de ação diante de diferentes contextos sociais, espaciais e temporais no ambiente de trabalho.

Este artigo conceitual tem, portanto, o objetivo de descrever a experiência com o método, explicitando os achados fortuitos acerca da dinâmica dos indivíduos pelas distintas categorias descritivas (concepções) ilustradas no mapa do espaço de resultado frente ao fenômeno em estudo. Assim, busca refletir o diálogo existente entre o método e o fenômeno.

Este artigo divide-se em cinco seções incluindo esta introdução: a segunda seção conceitua a fenomenografia como método de captura de concepções acerca de um fenômeno; a terceira seção descreve o emprego do método fenomenográfico no fenômeno estudado e as concepções emergentes, relatando a experiência com o emprego do método; a quarta seção revela os achados fortuitos referentes à fenomenografia, emergentes no decorrer da realização da pesquisa de campo e que foram validados em um grupo de foco; e a quinta seção conclui como os achados fortuitos e a experiência com o método podem contribuir para os estudos organizacionais. 


\section{Fenomenografia como Método de Captura das Concepções dos Indivíduos acerca de um Fenômeno}

O método fenomenográfico objetiva "descobrir e sistematizar formas de pensamento, em termos dos quais as pessoas interpretam aspectos da realidade que são significativos socialmente e supostamente compartilhados pelos membros de um tipo de sociedade" (Marton, 1981, p. 180). O método busca a compreensão de qualquer coisa que possa ser dita acerca de como o indivíduo apreende (percepção), cria sentido (significação e pensamento) e experimenta (ação e comportamento) um aspecto específico do seu mundo em relação ao fenômeno integral (Marton, 1981). A fenomenografia trabalha com o que é culturalmente aprendido e com o que é desenvolvido individualmente na relação do indivíduo com o mundo à sua volta. Ao trinômio percepção-pensamento-ação atribui-se o termo concepção, que se refere às diferentes maneiras como as pessoas vivenciam e dão sentido ao seu mundo (Sandberg, 2000).

A fenomenografia utiliza-se da perspectiva de segunda ordem, isto é, orienta-se para as diferentes ideias que os indivíduos possuem acerca da realidade ou de sua experiência nesta realidade. Traz a distinção entre uma crença formada sobre a realidade (perspectiva de primeira ordem) e as diferentes percepções da realidade, decorrentes das múltiplas experiências dos sujeitos no mundo (perspectiva de segunda ordem). Assim, o método coloca em suspenso os julgamentos, crenças e conceitos declarados acerca do mundo, abrindo-se para distintas visões de aspectos e partes que conformam o mundo (Akerlind, 2005a; Marton, 1981; Marton \& Booth, 1997).

Segundo Marton e Booth (1997), os indivíduos são portadores de diferentes modos de experimentar um fenômeno, que são fragmentos da realidade. Em outras palavras, nem todos os aspectos de um fenômeno e da situação na qual um indivíduo está incorporado são percebidos e estão presentes simultaneamente em sua consciência focal. Alguns modos são abstraídos, separados, isolados e experimentados um após o outro, em sequência. Portanto, certos modos de experimentar um fenômeno são mais completos, complexos e abrangentes do que outros, já que trazem mais partes ou aspectos do todo, simultaneamente, à consciência focal do indivíduo, enquanto certos modos serão mais parciais, simples e restritos.

De acordo com o método, as diferentes percepções dos indivíduos, reflexo das diferentes experiências ou modos de experimentar o fenômeno, são agrupadas em concepções ou categorias descritivas, que contêm dimensões acerca do fenômeno, trazendo os aspectos da natureza, da constituição e das relações sócio-espaço-temporal contextuais que caracterizam cada concepção do fenômeno. Cada uma das categorias individuais deve permanecer em clara relação com o fenômeno investigado, de modo que cada categoria diga algo distinto sobre um modo particular de experimentar o fenômeno. Como resultado do método, as concepções, ou categorias descritivas, são organizadas em um quadro denominado espaço de resultado (outcome space), que expõe uma relação lógica entre elas, frequentemente hierárquica, além de inclusiva e de complexidade crescente das concepções. $\mathrm{O}$ mapeamento do inter-relacionamento entre as concepções origina o mapa do espaço de resultados (Bowden \& Green, 2005), que procura ilustrar o fenômeno como um todo, o caminho percorrido pelos indivíduos através das categorias descritivas, da mais parcial, simples e restrita à mais completa, complexa e abrangente, sendo que cada concepção deve estar relacionada e inserida na concepção imediatamente seguinte, e assim sucessivamente (Marton \& Booth, 1997). O mapa do espaço de resultado é denominado por Marton (1981) de intelecto coletivo ou mente coletiva, por se tratar do arranjo de todas as concepções experimentadas e percebidas pelos indivíduos.

Dessa forma, os diferentes modos de experimentar o fenômeno, ou concepções, são partes componentes e relacionadas de modos mais complexos e completos de perceber o fenômeno. Esses modos podem ser compreendidos como diferentes camadas de consciência acerca das experiências individuais. Conforme os indivíduos experimentam repetidamente o fenômeno e aprendem a experimentá-lo de diferentes maneiras, vão percebendo novos contornos, ampliando sua consciência focal até mudar de concepção para a categoria seguinte, mais completa, ampla e complexa do que a 
anterior. No decorrer da vida, os indivíduos transitam pelas categorias, ou seja, pela estrutura do mapa de espaço de resultados (Bowden \& Green, 2005; Marton \& Booth, 1997). Os autores e pesquisadores, com o método, sugerem que esse fluxo se dá no sentido ascendente e crescente na hierarquia do mapa do espaço de resultado, da concepção mais simples para a de maior consciência focal dos indivíduos acerca do fenômeno (Bowden \& Green, 2005; Marton \& Both, 1997; Sandberg, 2000).

Embora o aspecto filosófico da fenomenografia tenha sido apresentado por Marton e Säljo (1976), Säljo (1979) e Marton (1981, 1986), os procedimentos metodológicos de coleta e análise dos dados próprios do método foram descritos na literatura, principalmente, nos trabalhos de Dall'alba e Hasselgren (1996), Marton e Booth (1997), special issue do periódico HERDSA (Entwistle, 1997), Bowden e Walsh (2000), Bowden e Green (2005) e, recentemente, Collier-Reed e Ingerman, (2013), além das contribuições críticas de Webb (1997) e Richardson (1999).

Cabe ressaltar que a fenomenografia nasceu na Área de Educação para auxiliar na compreensão de como os alunos experimentavam e concebiam o processo de aprendizagem e, consequentemente, aprendiam (Marton, 1981; Marton \& Booth, 1997; Marton \& Säljo, 1976; Säljo, 1979), sendo que, mais recentemente, investigou as concepções dos professores sobre o ensinar (Gibbings, 2008). No campo da Administração, especificamente em Estudos Organizacionais, a fenomenografia ingressou pela área de estudos de competências profissionais, gerenciais e organizacionais, talvez devido à fronteira entre educação profissional formal e treinamento para formação de competências para o trabalho, capitaneada por Sandberg (1991, 2000, 2001, 2009) e Dall'alba e Sandberg (1996). Seguiram-se os estudos de Partington e Young (2002), Pellegrinelli, Partington e Young (2003), Partington, Pellegrinelli e Young (2005), Chen e Partington (2006), Chen, Partington e Wang (2008), cujas pesquisas buscaram os modos de conceber competências gerenciais e concepções de gerência em programas complexos de gestão estratégica em diferentes culturas.

Entretanto, a revisão da literatura para o método em Estudos Organizacionais, do período de 1991 a 2014, revelou trinta e cinco artigos em periódicos internacionais e dez publicações nacionais (entre teses, artigos e publicações em anais). Pode-se inferir que o aparente limitado uso da fenomenografia se deve ao escasso conhecimento acerca da existência do método - muito recente, originado na área educacional, embora seja observado seu uso mais intensivo pelos pesquisadores oriundos das universidades que abraçaram a construção do método na Suécia e Austrália.

Desses países origina-se a existência de duas correntes do método fenomenográfico: a denominada Fenomenografia Pura, de Marton (Hasselgren \& Beach, 1997), e a Fenomenografia do Desenvolvimento, de Bowden (Bowden \& Green, 2005; Bowden \& Walsh, 2000). Pode-se observar que as correntes se diferenciam quanto aos procedimentos de realização da pesquisa, e não em seu propósito, já que ambas apresentam a preocupação constante com uma pesquisa teórica que sirva para auxiliar na realidade prática por meio das experiências vividas. Entretanto, no que diz respeito aos meios para a realização, especialmente na coleta e tratamento dos dados, pode-se observar que a Fenomenografia do Desenvolvimento é mais rígida e rigorosamente estruturada. Nela há uma preocupação intensa com os procedimentos para evitar a contaminação da entrevista, única forma possível de coleta de dados, e com o questionamento constante das categorias resultantes na análise dos dados, visando a assegurar a confiabilidade e a validade dos resultados (Bowden \& Walsh, 2000). A Fenomenografia Pura apresentase mais flexível ao permitir o uso de outras formas de coleta de dados, como relatos escritos e documentos, assim como se associa a outros métodos, tais como entrevista em grupo e observação direta, sem prejuízo ao rigor e à confiabilidade na forma de interpretar os dados (Hasselgren \& Beach, 1997).

A fenomenografia centra-se, portanto, na relação entre o sujeito e sua experiência com o fenômeno, em que o pesquisador se coloca como observador desta relação: do sujeito com sua percepção de mundo (Bowden \& Green, 2005). Já os métodos qualitativos interpretativos comumente empregados em estudos organizacionais, tais como fenomenologia interpretativa (Moustakas, 1994) e grounded theory method (Bryant \& Charmaz, 2007; Glaser \& Strauss, 2006), buscam, respectivamente, os significados atribuídos ao fenômeno pelo sujeito, centrando-se no indivíduo, e a interpretação das ligações entre experiências, ações e eventos vividos pelos sujeitos, centrando-se nos processos utilizados pelos sujeitos para lidar com o fenômeno. Por sua vez, a análise de conteúdo (Bardin, 1979) e a análise 
do discurso (G. Brown \& Yule, 1988) buscam os significados das estruturas pelas quais os sujeitos expressam o fenômeno, centrando-se, assim, no próprio fenômeno. Em relação à abordagem de pesquisa, Marton (1981) ressalta o contraste ao expor que a fenomenografia se refere a qualquer coisa (anything) que possa ser dita sobre como os indivíduos percebem, conceituam (pensam) e experimentam (agem) o fenômeno, enquanto os demais métodos procuram saber tudo (everything) sobre determinados aspectos do fenômeno.

Em termos de resultado, a distinção mais relevante é que a fenomenografia visa a inter-relação entre os significados expressos nas categorias descritivas resultantes, enquanto os demais métodos qualitativos tendem a gerar categorias estanques, classificatórias e independentes entre si em seus significados (Bowden \& Green, 2005). Conforme expressa Bowden (2005), o objetivo da fenomenografia é "mapear, e não catalogar" (p. 26):

Se você deseja usar os dados para obter um cenário dos diferentes tipos de contextos existentes, então o mapa de resultados, holístico, é preferível. Para o bem ou para o mal, a fenomenografia está interessada nele. Pode ser um desapontamento para pesquisadores que gostariam de obter resultados que permitissem detalhadas comparações entre casos e tipos. (Bowden, 2005, p. 27)

Isso não significa que outros métodos qualitativos não procurem apresentar em seus resultados a inter-relação entre categorias, ou seja, a relação processual e complementar entre si, como sugere o grounded theory method (Corbin \& Strauss, 1990). Porém, no método fenomenográfico, cada categoria descritiva representa um fragmento de compreensão do fenômeno/realidade pela perspectiva de entendimento dos indivíduos, que, ao ser mapeada e ao apresentar o seu inter-relacionamento com as demais categorias, aporta uma compreensão mais completa e abrangente dessa realidade (Akerlind, 2005a). Conforme já dito, cada categoria está conceitualmente contida dentro da categoria seguinte em vários aspectos ou dimensões, ampliando a consciência focal acerca destes mesmos aspectos ou dimensões (Akerlind, 2005b; Bowden, 2005; Marton \& Booth, 1997; Sandberg, 2000). Portanto, o objetivo do método é o mapeamento inclusivo e hierárquico de concepções, que é exemplificado mais a frente no tópico 3, acerca das concepções e espaço de resultado, e na Figura 1, Mapa do Espaço de Resultado.

Além disso, em sua experiência com o método, Akerlind (2005a) destaca que a fenomenografia se distingue das demais metodologias qualitativas ao dar ênfase: às percepções acerca do fenômeno com a perspectiva de segunda ordem, refutando crenças tidas como verdades; à percepção inserida no contexto sócio-espaço-temporal, em que o indivíduo pode vivenciar o mesmo fenômeno de diversos modos sob circunstâncias diferentes; e à descrição da experiência no nível coletivo, e não individual, expondo modos de conceber partes de um fenômeno integral.

\section{Fenomenografia em Ação: O Emprego do Método sobre o Fenômeno da Valoração do Conhecimento}

O estudo que originou os achados ilustrativos do emprego do método, aqui apresentados, buscou compreender como os indivíduos percebiam, interpretavam, significavam e atribuíam valor de importância ao conhecimento nas organizações, uma vez que tais aspectos pareciam influenciar as consequentes atitudes de adoção, aplicação e internalização dos conhecimentos tanto pelos indivíduos quanto pela organização. Objetivou analisar os diferentes modos (concepções) pelos quais os membros organizacionais percebem e experimentam a valoração do conhecimento no contexto do trabalho.

O estudo adotou a perspectiva do conhecimento como o conhecer (knowing) na prática e na ação: a visão practice-based theorizing (Gherardi, 2000; Orlikowski, 2002). Definiu-se a valoração do conhecimento como um senso coletivo de apreciação mútua, construído socialmente, em que um grupo, em determinado contexto, atribui valor a um mesmo resultado emergente de uma atividade (Swart, 2011). Assim, foram contempladas as experiências de valoração do conhecimento trazidas pelas 
narrativas dos sujeitos, emergentes e dadas na ação e na prática de trabalhar em um contexto específico (J. S. Brown \& Duguid, 1991; Latour, 2012; Lave \& Wenger, 1991; Orlikowski, 2002).

Para acessar as concepções dos sujeitos acerca do fenômeno da valoração do conhecimento no contexto do trabalho, utilizaram-se os procedimentos de seleção dos sujeitos, roteiro, formato de entrevista e modo de análise dos dados, conforme descritos em Sandberg (2000), Bowden e Walsh (2000), Akerlind (2005a, 2005b) e Bowden e Green (2005), tendo por base a fenomenografia pura de Marton (1981) e Marton e Booth (1997).

\section{Seleção dos sujeitos e planejamento da amostra intencional}

O método fenomenográfico preconiza a realização de vinte a trinta entrevistas em profundidade, semiestruturadas, planejando-se a amostra intencional para a busca de variedade nos sujeitos participantes, a fim de trazer os diferentes modos de experimentar o fenômeno (Akerlind, 2005a; Bowden \& Green, 2005). No caso ora ilustrado, as entrevistas foram conduzidas com vinte e dois profissionais de $\mathrm{RH}$, considerando a variação intencional: (a) por cargo, de analista a vice-presidente; (b) por tempo de experiência profissional, de 3 a 36 anos; (c) por tipo de empresa e porte, em vinte e duas empresas nacionais e multinacionais, privadas, de médio a grande porte; (d) por tipo de formação profissional. A Tabela 1 exibe a amostra planejada previamente à pesquisa e a efetivamente obtida.

Tabela 1

Variação Demográfica da Amostra Intencional

\begin{tabular}{|c|c|c|}
\hline Grupos & $\begin{array}{l}\text { Variação Proposta para o Número de } \\
\text { Sujeitos Entrevistados }\end{array}$ & $\begin{array}{l}\text { Variação Obtida de Sujeitos } \\
\text { Entrevistados }\end{array}$ \\
\hline $\begin{array}{l}\text { Tempo de Atuação } \\
\text { Profissional }\end{array}$ & $\begin{array}{l}4 \text { subgrupos, com } 5 \text { a } 8 \text { entrevistados: } \\
\text {. Até } 5 \text { anos; } \\
\text {. De } 6 \text { a } 15 \text { anos; } \\
\text {. De } 16 \text { a } 25 \text { anos; } \\
\text {. Acima de } 26 \text { anos. }\end{array}$ & $\begin{array}{l}\text { Até } 5 \text { anos: } 4 \\
\text { De } 6 \text { a } 15 \text { anos: } 8 \\
\text {. De } 16 \text { a } 25 \text { anos: } 7 \\
\text {. Acima de } 26 \text { anos: } 3\end{array}$ \\
\hline Posição/Cargo & $\begin{array}{l}\text { Analista/coordenação: } 6 \text { a } 8 \\
\text { Gerência intermediária: } 8 \text { a } 12 \\
\text {. Alta gerência/diretoria: } 6 \text { a } 8\end{array}$ & $\begin{array}{l}\text { Analista/coordenação/especialista: } 9 \\
\text {. Gerência intermediária: } 8 \\
\text {. Alta gerência/diretoria: } 5\end{array}$ \\
\hline Tipo de Empresa & $\begin{array}{l}\text { Indústrias de setores econômicos diversos } \\
\text { Nacional e multinacional privadas } \\
2 \text { subgrupos: } \\
\text {. Pequeno e médio porte: } 6 \text { a } 10 \\
\text { Grande porte: } 10 \text { a } 14\end{array}$ & $\begin{array}{l}18 \text { indústrias } \\
\text { Nacional: } 12 \\
\text { Multinacional: } 10 \\
\text { Médio porte: } 8 \\
\text {. Grande porte: } 14\end{array}$ \\
\hline Formação & $\begin{array}{l}\text { Administração: } 6 \text { a } 8 \\
\text { Psicologia: } 6 \text { a } 8 \\
\text {. Economia, Engenharia, outros: } 8 \text { a } 12\end{array}$ & $\begin{array}{l}\text { Administração: } 6 \\
\text { Psicologia: } 9 \\
\text {. Economia, Engenharia, outros: } 7\end{array}$ \\
\hline
\end{tabular}

Nota. A Tabela 1 ilustra, na segunda coluna, o planejamento feito pelos autores para obtenção desejada de variação na amostra de sujeitos entrevistados, conforme preconiza o método. A terceira coluna apresenta a variação obtida, em que a busca por variação na amostra de sujeitos entrevistados foi atingida. Fonte: Elaborada pelos autores.

Bowden e Green (2005) entendem que esse número de entrevistas é considerado o suficiente para assegurar a variação nos modos de ver o fenômeno e, ao mesmo tempo, torna viável o manejo do volume de dados, uma vez que todas as entrevistas serão tratadas simultaneamente (ver seção Tratamento e Análise dos Dados). Portanto, a fenomenografia se afasta do debate recorrente em pesquisas qualitativas acerca da obtenção de saturação teórica dos dados. Entretanto, na presente experiência de pesquisa, a 
saturação teórica foi observada na $17^{a}$ entrevista, sugerindo que o mínimo de 20 entrevistas, definido pelo método, parece de fato contemplar fenômenos complexos com relativa variação da amostra intencional.

\section{Instrumento e coleta de dados}

É recomendado que a entrevista fenomenográfica seja semiestruturada e em profundidade. O roteiro é composto por um cenário que delimita o tema ao qual a conversa irá se ater; uma pergunta central que pede ao sujeito para narrar a experiência vivida que melhor exemplifica o fenômeno (situação na qual o fenômeno ocorreu de modo prototípico); questões de apoio tipo o quê? como?, a fim de capturar o que é e como é concebido o fenômeno; e por quê?, para compreender a percepção e o pensamento/teorização por trás da ação (Akerlind, 2005a; Sandberg, 2000). Deve-se evitar a introdução de novos temas durante a realização da entrevista, a expressão de opinião e intervenção do entrevistador na fala do entrevistado, assim como garantir que os participantes não tenham acesso prévio ao roteiro (Bowden \& Green, 2005). A fenomenografia objetiva capturar a concepção do fenômeno, ou seja, deseja-se que o entrevistado elabore o que é concebido (pensamento acerca do significado da realidade), como é concebido (ação em que o significado ocorre) e a relação entre ambos (reflexão sobre a ação na situação exemplificada) no momento da realização da entrevista, evitando teorizações prévias.

Na pesquisa realizada, pediu-se aos participantes que: (a) descrevessem sua trajetória profissional, como questão introdutória; (b) apresentassem sua definição do que é conhecimento, a fim de auxiliar na preparação à pergunta central; (c) detalhassem a situação na qual tiveram o conhecimento mais e menos valorado no contexto do trabalho - pergunta central; e (d) explorassem em que circunstâncias, como, com quem e por que o fenômeno ocorreu - perguntas de apoio. Ressalta-se que a entrevista fenomenográfica é bastante difícil para o entrevistado, corroborando Bowden e Green (2005), uma vez que o sujeito é impelido a teorizar acerca de situações e temas talvez nunca antes avaliados por ele. Além disso, a impossibilidade de intervenção do entrevistador, para não induzir a resposta ao entrevistado, precisa ser compensada com a rearticulação da fala do próprio entrevistado, a fim de evitar frieza ou distanciamento no momento da entrevista, o que também agrega dificuldade ao entrevistador.

\section{Tratamento e análise dos dados}

As vinte e duas entrevistas resultaram em $21 \mathrm{~h} 09 \mathrm{~m}$ de material líquido gravado, ou seja, excluídos o consentimento esclarecido e o cenário da entrevista, e geraram 352 páginas transcritas para análise. Conforme preconizado, todas as entrevistas foram lidas três vezes na totalidade, em sequência, a fim de separar aquelas mais dissimilares e agrupar as mais similares entre si, em termos de significado do fenômeno (Akerlind, 2005b; Sandberg, 2000), de forma que os indivíduos fossem descontextualizados de suas narrativas individuais (Bowden \& Walsh, 2000; Marton \& Booth, 1997). As entrevistas devem ser consideradas em sua íntegra e observa-se o que concebem no conjunto total de entrevistas ( $\mathrm{O}$ que dizem em seu conjunto?) e na relação entre elas (O que esse sujeito concebe? Onde se encaixa no todo, no conjunto total de entrevistas?).

O objetivo da fenomenografia é abrir um grupo restrito de concepções, encontrando os aspectos que façam emergir a inter-relação lógica, hierárquica e inclusiva entre o número adequado de concepções (Akerlind, 2005b), que dará origem ao mapa do espaço de resultado. Apenas após esse procedimento, procede-se à análise do conteúdo de cada entrevista, a fim de codificar as dimensões encontradas nos relatos, assim como refinar, rearranjar e confirmar as concepções para, então, detalhar a categoria descritiva. Deve-se considerar a dificuldade de manejar simultaneamente todas as entrevistas para fazer emergir as concepções iniciais, ponderando o conteúdo da massa de dados contida em centenas de páginas de transcrição. Esse aspecto é relevante também, pois somente após o pensamento sintético ter dado origem às categorias que se inter-relacionam, os dados são tratados por partes, ou seja, as entrevistas são desmembradas de modo analítico. Esse processo pode trazer desafios ao pesquisador qualitativo acostumado ao pensamento analítico, que vai aos detalhes dos dados para fazer emergir a síntese. No estudo ora mencionado, a etapa analítica foi feita com auxílio do Atlas-Ti. 
Akerlind (2005b) relata que, dependendo da complexidade do fenômeno, da quantidade de material a ser manipulado e da variação da amostra intencional, o refinamento de categorias varia de três a seis meses. O tempo de análise dos dados da pesquisa aqui ilustrada, desde a leitura e separação da massa das vinte e duas entrevistas em categorias iniciais até a definição das cinco categorias finais com dimensões refinadas, levou cerca de três meses, em tempo integral. Essa circunstância do método limita a exploração para apenas uma ou duas questões centrais por projeto de pesquisa.

Bowden e Walsh (2005), em sua corrente fenomenográfica do desenvolvimento, mais rigidamente estruturada, consideram que a validade, a confiabilidade das categorias encontradas e o rigor na pesquisa são assegurados pelo questionamento constante dos achados, feito por pares. O estudo realizado utilizou-se da fenomenografia pura (Marton, 1981; Marton \& Booth, 1997), fundamentada na capacidade interpretativa do pesquisador, e mais flexível e aberta ao entendimento do fenômeno por meio da conjugação com outros métodos qualitativos.

Desse modo, a fim de validar as categorias descritivas emergentes - e os achados fortuitos relativos ao método, procedeu-se a um grupo de foco (Goldman \& McDonald, 1987). Partington et al. (2005) realizaram iniciativa similar de triangulação de dados, segundo asserção de Denzin (1978), com a realização de um workshop com os participantes do estudo, com o objetivo de validar e enriquecer a compreensão dos seus resultados (Denzin \& Lincoln, 2000). Reforçando tal aspecto, Denzin e Lincoln (2000, p. 5) asseveram:

A triangulação não é uma ferramenta ou uma estratégia de validação, é uma alternativa à validação. A combinação de diferentes perspectivas metodológicas, diversos materiais empíricos e a participação de vários investigadores em um só estudo devem ser vistos como uma estratégia para acrescentar rigor, amplitude, complexidade, riqueza e profundidade a qualquer investigação.

O grupo de foco do presente estudo foi conduzido com cinco participantes (entrevistados 2, 4, 5 , 6 e 10) prototípicos e representativos de quatro categorias distintas, e também com sujeitos que transitaram pela estrutura no sentido descendente ou de modo dinâmico. Teve duração de 141 minutos de gravação para posterior resgate dos dados.

\section{Concepções, espaço de resultado e mapa do espaço de resultado para a valoração do conhecimento no contexto do trabalho}

A análise das entrevistas em seu conjunto, para identificar as concepções emergentes e, individualmente, para salientar as dimensões componentes, fez emergir cinco concepções para descrever o fenômeno da valoração do conhecimento no contexto do trabalho. Essas categorias acerca da significação do Conhecimento Valorado (CV) foram arrumadas em ordem ascendente, hierárquica e inclusiva: a concepção seguinte incorporou os conceitos da categoria anterior e os expandiu na direção da ampliação da consciência dos indivíduos a respeito da experiência com o fenômeno. Foram elas:

Aplicação no Trabalho: Alinhamento entre conhecimento de valor para o indivíduo - técnico, objetivado e estocável - e a necessidade estratégica da organização, visando a um funcionamento perfeito, eficiência e eficácia. A natureza do conhecimento é individual, baseada em conhecimento técnico, com aplicação direta no trabalho e na geração de resultados. O conhecimento valorado deveria ser planejado, nas dimensões individual e organizacional. O indivíduo é a organização.

Consideração do Trabalho-Indivíduo: Ajustamento entre conhecimento de valor e consideração do indivíduo nas atividades da organização. Há uma ação reflexiva: o indivíduo precisa ser reconhecido para valorar a si mesmo e age para ter o conhecimento que acredita que a organização valora. A natureza do conhecimento é individual, fortemente baseada em conhecimento técnico e em experiência prática para aplicação e resultado no trabalho, para que o sujeito se ajuste e seja considerado pela organização. O indivíduo busca encaixar-se na organização.

Realização do Indivíduo no Trabalho: Associação entre conhecimento de valor - que é avaliado pelo indivíduo e que constrói a organização - e o conhecimento organizacional. A ação conjunta de 
trabalhar e solucionar problemas emergentes no trabalho move o sujeito. A natureza do conhecimento vai para além do conhecimento técnico e prático: é processual e compartilhada na ação de trabalhar, uma junção de conhecimentos individuais. O conhecimento valorado insere-se na prática e na ação de trabalhar, associando o conhecimento individual e o organizacional. O indivíduo é um com a organização.

- Transformação do Indivíduo e do Trabalho: Antagonismo entre conhecimento de valor - que disputa o status quo para transformar a organização - e o exercício de controle pelo poder e/ou hierarquia, geralmente realizado pelo líder ou gestor. A natureza do conhecimento é compartilhada, coletiva na ação de trabalhar, tal como na concepção anterior. Porém, na impossibilidade de se processar desse modo, transforma-se em questionadora, disputada e conflituosa. O indivíduo não é a organização.

- Criação Emergente para a Vida: Dissociação entre conhecimento de valor - que questiona o paradigma vigente e origina inovação de longo prazo - e o conhecimento que traz resultado de curto prazo valorado pelo líder, chefia ou alta gestão. A natureza do conhecimento é compartilhada na ação de trabalhar, emergente da ação e questionadora. Envolve a assunção de risco e aprendizagem com o erro. O conhecimento valorado serve à vida do sujeito, é maior que a organização. O indivíduo é diferente da organização.

O espaço de resultado com as dimensões descritas encontra-se na Tabela 2 para fins de exemplificação do método fenomenográfico. As dimensões emergentes descritas na análise foram: a natureza do conhecimento; a perspectiva dimensional de interação social do indivíduo com os grupos e organização frente ao fenômeno; os mecanismos de identificação com a identidade organizacional; o contexto sócio-espaço-temporal; pessoas de influência frente à valoração do conhecimento; e recontextualização do arranjo estrutural organizacional encontrado em cada categoria, cujo somatório deu origem à concepção de valoração do conhecimento no contexto do trabalho. 
Tabela 2

\section{Espaço de Resultado para as Concepções acerca da Valoração do Conhecimento no Contexto do Trabalho}

\begin{tabular}{|c|c|c|c|c|c|}
\hline Dimensão & Aplicação no Trabalho & $\begin{array}{c}\text { Consideração } \\
\text { (Reconhecimento) do } \\
\text { Trabalho-Indivíduo }\end{array}$ & $\begin{array}{c}\text { Realização do Indivíduo no } \\
\text { Trabalho }\end{array}$ & $\begin{array}{c}\text { Transformação do } \\
\text { Indivíduo e do } \\
\text { Trabalho }\end{array}$ & $\begin{array}{c}\text { Criação Emergente para a } \\
\text { vida }\end{array}$ \\
\hline Conceito & $\begin{array}{l}\text { Alinhamento entre CV } \\
\text { pelo indivíduo - técnico, } \\
\text { objetivado e estocável - e } \\
\text { a necessidade estratégica } \\
\text { da organização, visando } \\
\text { um funcionamento } \\
\text { perfeito, eficiência e } \\
\text { eficácia. }\end{array}$ & $\begin{array}{l}\text { Ajustamento entre CV e } \\
\text { consideração do indivíduo } \\
\text { para atividades da } \\
\text { organização. Ação reflexiva: } \\
\text { o indivíduo precisa ser } \\
\text { reconhecido para valorar a si } \\
\text { mesmo; assim, age para } \\
\text { ter/ser o conhecimento que a } \\
\text { organização valora. }\end{array}$ & $\begin{array}{l}\text { Associação entre CV e } \\
\text { conhecimento organizacional. O } \\
\mathrm{CV} \text { é avaliado pelo indivíduo, } \\
\text { estabelecendo o modo pelo qual o } \\
\text { trabalho será desempenhado na } \\
\text { organização. } \\
\text { Ação conjunta de trabalhar e } \\
\text { solucionar problemas emergentes } \\
\text { no trabalho move o indivíduo para } \\
\text { resultados organizacionais. }\end{array}$ & $\begin{array}{l}\text { Antagonismo entre } \mathrm{CV}, \\
\text { que questiona o status } \\
\text { quo, transforma a } \\
\text { organização, e o } \\
\text { exercício de controle } \\
\text { pelo poder e/ou } \\
\text { hierarquia, geralmente } \\
\text { realizado pelo líder ou } \\
\text { gestor. }\end{array}$ & $\begin{array}{l}\text { Dissociação entre } \mathrm{CV} \text {, que } \\
\text { questiona o paradigma } \\
\text { vigente e traz inovação de } \\
\text { longo prazo, e o } \\
\text { conhecimento que traz } \\
\text { resultado de curto prazo, } \\
\text { valorado pelo líder, chefia, } \\
\text { ou alta gestão. }\end{array}$ \\
\hline $\begin{array}{l}\text { Natureza do } \\
\text { Conhecimento }\end{array}$ & $\begin{array}{l}\text { Individual, baseado em } \\
\text { conhecimento técnico, } \\
\text { com aplicação direta no } \\
\text { trabalho e na geração de } \\
\text { resultados. } \\
\text { Objeto estocável, deve } \\
\text { ser planejado, na } \\
\text { dimensão individual e } \\
\text { organizacional. }\end{array}$ & $\begin{array}{l}\text { Individual, fortemente } \\
\text { baseado em conhecimento } \\
\text { técnico e em experiência } \\
\text { prática, para aplicação e } \\
\text { resultado no trabalho, a fim } \\
\text { de ser considerado pela } \\
\text { organização. }\end{array}$ & $\begin{array}{l}\text { Compartilhado na ação de } \\
\text { trabalhar, uma junção de } \\
\text { conhecimentos individuais; é } \\
\text { processual. Insere-se na prática e } \\
\text { na ação de trabalhar. CV alinha } \\
\text { conhecimento individual e } \\
\text { organizacional. }\end{array}$ & $\begin{array}{l}\text { Compartilhado, coletivo } \\
\text { na ação de trabalhar, } \\
\text { questionador, disputado } \\
\text { e conflituoso. }\end{array}$ & $\begin{array}{l}\text { Compartilhado, coletivo na } \\
\text { ação de trabalhar, } \\
\text { questionador, emergente da } \\
\text { ação. Envolve assunção de } \\
\text { risco e aprendizagem com o } \\
\text { erro. CV é para a vida, é } \\
\text { maior que a organização. }\end{array}$ \\
\hline $\begin{array}{l}\text { Perspectiva } \\
\text { Dimensional }\end{array}$ & Organização & $\begin{array}{l}\text { Organização > Grupo > } \\
\text { Indivíduo }\end{array}$ & Indivíduo > Grupo > Organização & Indivíduo > Organização & Indivíduo \\
\hline $\begin{array}{l}\text { Mecanismos de } \\
\text { Identificação }\end{array}$ & Eu sou a organização. & Eu busco ser a organização. & Eu sou um com a organização. & $\begin{array}{l}\text { Eu não sou a } \\
\text { organização. }\end{array}$ & $\begin{array}{l}\text { Eu sou diferente da } \\
\text { organização. }\end{array}$ \\
\hline
\end{tabular}


Tabela 2 (continuação)

\begin{tabular}{|c|c|c|c|c|c|}
\hline Dimensão & Aplicação no Trabalho & $\begin{array}{c}\text { Consideração } \\
\text { (Reconhecimento) do } \\
\text { Trabalho-Indivíduo }\end{array}$ & $\begin{array}{c}\text { Realização do Indivíduo no } \\
\text { Trabalho }\end{array}$ & $\begin{array}{c}\text { Transformação do } \\
\text { Indivíduo e do } \\
\text { Trabalho }\end{array}$ & $\begin{array}{c}\text { Criação Emergente para a } \\
\text { vida }\end{array}$ \\
\hline Contexto Social & $\begin{array}{l}\text { Quase inexistente. } \\
\text { Relação centrada no eu- } \\
\text { resultado para a } \\
\text { organização. Pessoas são } \\
\text { meios/recursos para } \\
\text { aplicar o conhecimento e } \\
\text { chegar ao resultado. }\end{array}$ & $\begin{array}{l}\text { É por meio da equipe que os } \\
\text { resultados são obtidos, } \\
\text { concorrendo para a } \\
\text { consideração da competência } \\
\text { do sujeito. }\end{array}$ & $\begin{array}{l}\text { É primordial e pressuposto: é por } \\
\text { onde o conhecimento se constrói e } \\
\text { o indivíduo se realiza na entrega } \\
\text { conjunta. A interação entre as } \\
\text { pessoas conjuga conhecimentos } \\
\text { que são postos em prática na } \\
\text { organização. }\end{array}$ & $\begin{array}{l}\text { É por onde a } \\
\text { transformação ocorre - } \\
\text { do controle e poder para } \\
\text { a participação (ou não) } \\
\text { da rede de } \\
\text { relacionamento que } \\
\text { impede ou facilita as } \\
\text { ações. }\end{array}$ & $\begin{array}{l}\text { É pressuposto para a criação } \\
\text { de CV. O conhecimento está } \\
\text { nos indivíduos, nas pequenas } \\
\text { coisas do dia a dia, e emerge } \\
\text { da/na interação social. }\end{array}$ \\
\hline Contexto Espacial & $\begin{array}{l}\text { É pressuposto para que o } \\
\text { conhecimento de valor se } \\
\text { faça visível (resultado } \\
\text { eficaz): estruturas } \\
\text { definidas e processos } \\
\text { formais instaurados, } \\
\text { cultura organizacional e } \\
\text { valores disseminados são } \\
\text { ordenamentos } \\
\text { necessários para } \\
\text { aplicação do } \\
\text { conhecimento. }\end{array}$ & $\begin{array}{l}\text { É por meio da relação da } \\
\text { estrutura centralizada e } \\
\text { tradicional com a } \\
\text { estruturação das atividades e } \\
\text { processos que o CV } \\
\text { (reconhecimento) ocorre: os } \\
\text { processos e práticas em } \\
\text { estruturação visam medir e } \\
\text { controlar as pessoas, as } \\
\text { tarefas e o desempenho, } \\
\text { reproduzindo o sistema de } \\
\text { reconhecimento. }\end{array}$ & $\begin{array}{l}\text { É condição para a interação social } \\
\text { ocorrer. É fluido e flexível, com } \\
\text { estruturas descentralizadas, com } \\
\text { alto grau de autonomia, gestão } \\
\text { participativa e grande possibilidade } \\
\text { de intervenção nas tarefas e } \\
\text { processos ou criação destes. }\end{array}$ & $\begin{array}{l}\text { É o pressuposto para o } \\
\text { conhecimento que } \\
\text { transforma a } \\
\text { organização: a posição } \\
\text { ocupada, a hierarquia } \\
\text { estabelecida. A caixa } \\
\text { hierárquica } \\
\text { define/contém as } \\
\text { competências que } \\
\text { autorizam os sujeitos. }\end{array}$ & $\begin{array}{l}\text { É condição para o CV } \\
\text { emergir: descentralização } \\
\text { com alto grau de autonomia } \\
\text { e pouca hierarquia, em } \\
\text { situações de baixa } \\
\text { estruturação das atividades } \\
\text { em situações complexas e } \\
\text { únicas. }\end{array}$ \\
\hline $\begin{array}{l}\text { Contexto } \\
\text { Temporal }\end{array}$ & $\begin{array}{l}\text { É por meio do } \\
\text { planejamento, das } \\
\text { atividades detalhadas e } \\
\text { alinhadas, em sequência, } \\
\text { que o resultado eficaz é } \\
\text { obtido e o conhecimento } \\
\text { se torna presente. }\end{array}$ & $\begin{array}{l}\text { É inexistente para os sujeitos. } \\
\text { O tempo é dado pela } \\
\text { liderança na demanda pelas } \\
\text { atividades e tarefas, e não } \\
\text { pelo ciclo das atividades } \\
\text { (pouco estruturadas) ou do } \\
\text { ambiente de negócios. }\end{array}$ & $\begin{array}{l}\text { É inerente ao trabalho, já que a } \\
\text { necessidade de solução para um } \\
\text { problema ou desenvolvimento de } \\
\text { uma atividade surge na sua } \\
\text { realização. }\end{array}$ & $\begin{array}{l}\text { É inerente ao trabalho } \\
\text { para cumprir com as } \\
\text { demandas estabelecidas } \\
\text { pela liderança ou pela } \\
\text { hierarquia. }\end{array}$ & $\begin{array}{l}\text { É por onde a criação do CV } \\
\text { ocorre, no tempo indefinido } \\
\text { de fazer algo novo emergir } \\
\text { para resolver um problema } \\
\text { ou desenvolver uma } \\
\text { atividade no trabalho. }\end{array}$ \\
\hline
\end{tabular}


Tabela 2 (continuação)

\begin{tabular}{|c|c|c|c|c|c|}
\hline Dimensão & Aplicação no Trabalho & $\begin{array}{c}\text { Consideração } \\
\text { (Reconhecimento) do } \\
\text { Trabalho-Indivíduo }\end{array}$ & $\begin{array}{c}\text { Realização do Indivíduo no } \\
\text { Trabalho }\end{array}$ & $\begin{array}{l}\text { Transformação do } \\
\text { Indivíduo e do } \\
\text { Trabalho }\end{array}$ & $\begin{array}{c}\text { Criação Emergente para a } \\
\text { vida }\end{array}$ \\
\hline $\begin{array}{l}\text { Pessoas de } \\
\text { Influência no CV }\end{array}$ & $\begin{array}{l}\text { A estratégia; a alta } \\
\text { gestão; uma cadeia } \\
\text { despersonalizada. } \\
\text { Reificação da } \\
\text { organização e não } \\
\text { corporificação do Quem, } \\
\text { reprodução mimética da } \\
\text { Organização. }\end{array}$ & $\begin{array}{l}\text { A consideração das pessoas é } \\
\text { fundamental para o } \\
\text { indivíduo: diretor, gerente } \\
\text { direto, equipe e pares } \\
\text { exercem influência e } \\
\text { reforçam o CV. O líder } \\
\text { suporta/endossa o indivíduo. }\end{array}$ & $\begin{array}{l}\text { O líder, chefia e alta gestão } \\
\text { estabelecem o ambiente propício, } \\
\text { a cultura organizacional. } \\
\text { O indivíduo e seus pares e equipe } \\
\text { constroem o CV. }\end{array}$ & $\begin{array}{l}\text { O líder, chefia ou alta } \\
\text { gestão, através do poder } \\
\text { (ou da posição) e das } \\
\text { escolhas definidas para a } \\
\text { organização. }\end{array}$ & $\begin{array}{l}\text { Geralmente o líder, chefia ou } \\
\text { alta gestão, mas não do } \\
\text { conhecimento de valor; e } \\
\text { sim aquele que traz o } \\
\text { resultado. } \\
\text { O indivíduo valora o } \\
\text { conhecimento de valor real. }\end{array}$ \\
\hline $\begin{array}{l}\text { Recontextualização } \\
\text { da Estrutura } \\
\text { Organizacional }\end{array}$ & $\begin{array}{l}\text { Estrutura multinacional, } \\
\text { com alto grau de } \\
\text { estruturação e } \\
\text { formalização das } \\
\text { atividades e processos. }\end{array}$ & $\begin{array}{l}\text { Estrutura tradicional e/ou } \\
\text { familiar, com baixo grau de } \\
\text { estruturação/formalização } \\
\text { das atividades e processos. } \\
\text { Centralização das decisões e } \\
\text { do poder. }\end{array}$ & $\begin{array}{l}\text { Estrutura nacional de grande porte, } \\
\text { com gestão profissional. Médio } \\
\text { grau de estruturação/ formalização } \\
\text { das tarefas e processo. } \\
\text { Descentralização das decisões com } \\
\text { autonomia. }\end{array}$ & $\begin{array}{l}\text { Estrutura multinacional } \\
\text { ou nacional de grande } \\
\text { porte, derivadas de } \\
\text { empresas públicas } \\
\text { privatizadas. Alto grau } \\
\text { de estruturação das } \\
\text { atividades e processos. } \\
\text { Alta centralização das } \\
\text { decisões, baixo grau de } \\
\text { autonomia, } \\
\text { hierarquizada. }\end{array}$ & $\begin{array}{l}\text { Estrutura multinacional e/ou } \\
\text { estrutura nacional de grande } \\
\text { porte com gestão } \\
\text { profissional. Alto grau de } \\
\text { formalização das tarefas e } \\
\text { processos existentes, mas } \\
\text { sujeita a novos processos ad } \\
\text { hoc, pela dinâmica do } \\
\text { ambiente. Descentralização } \\
\text { das decisões com autonomia. }\end{array}$ \\
\hline $\begin{array}{l}\text { Sujeitos } \\
\text { em Trânsito entre } \\
\text { concepções }\end{array}$ & $3,8,18$ & $\mid \begin{array}{l}4,11,15,17 \\
<-----------1 z, 46\end{array}$ & $\begin{array}{l}1,5,10,13 \\
------------\end{array}$ & $6,7,21$ & $\begin{array}{l}2,9,19 \\
-\cdot-\cdot-\cdot-\cdot-\cdot-\cdot \cdot-\cdot-\cdot-\cdot .\end{array}$ \\
\hline
\end{tabular}

Nota. Fonte: Elaborada pelos autores. 
O mapa do espaço de resultado, apresentado no modelo A da Figura 1, ilustra a hierarquia de inter-relação entre as concepções acerca da valoração do conhecimento no contexto do trabalho, por onde os sujeitos transitam, conforme preconizado pelos autores do método, ou seja, sempre no sentido ascendente de ampliação da consciência focal e complexidade da concepção. Os achados relacionados ao método, que serão discutidos na próxima seção, reconfiguram o mapa do espaço de resultado, representados nas nos modelos B e C da Figura 1. Antecipa-se que o modelo B da Figura apresenta o movimento bidirecional de trânsito dos sujeitos sentido acima e abaixo na hierarquia de concepções. $\mathrm{O}$ modelo C da Figura 1, por sua vez, é a contribuição dos participantes do grupo de foco, que entenderam que os círculos inclusivos representam melhor as relações entre concepções: bidirecionais, em um continuum ininterrupto, mais dinâmicas e fluidas.

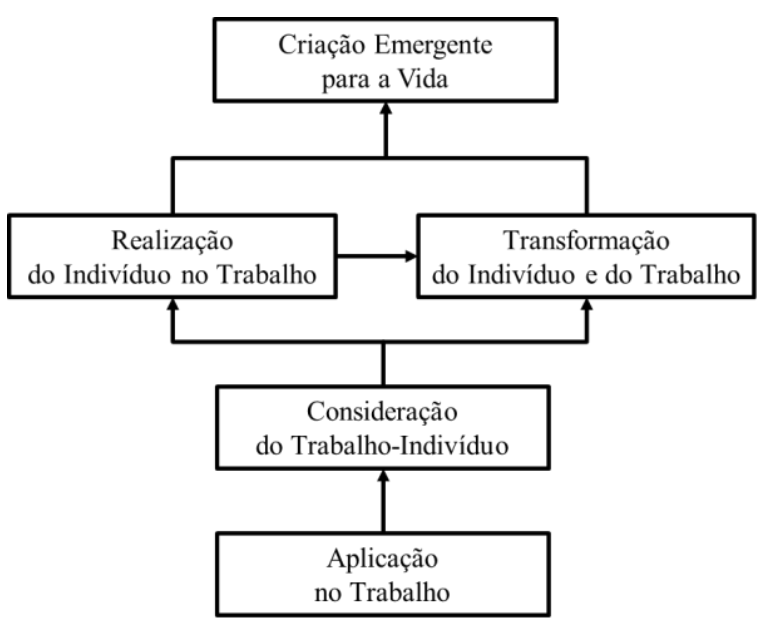

A

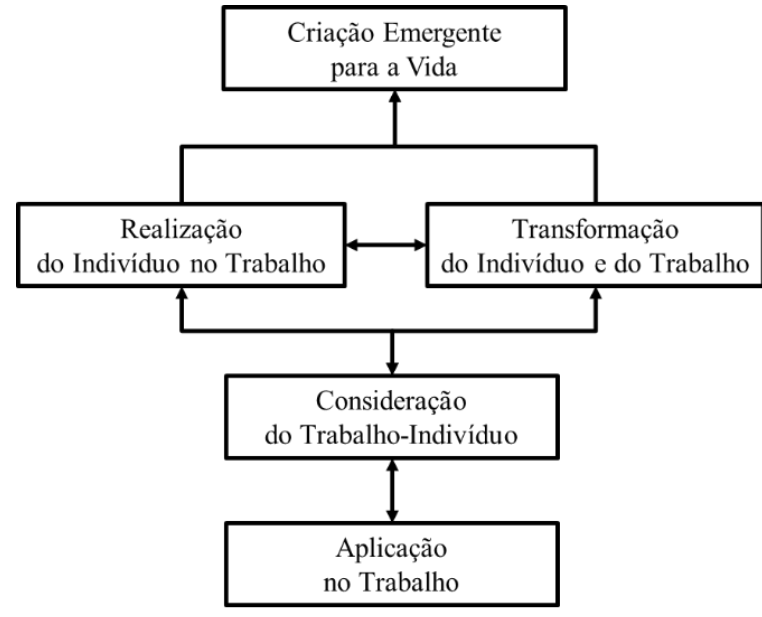

B

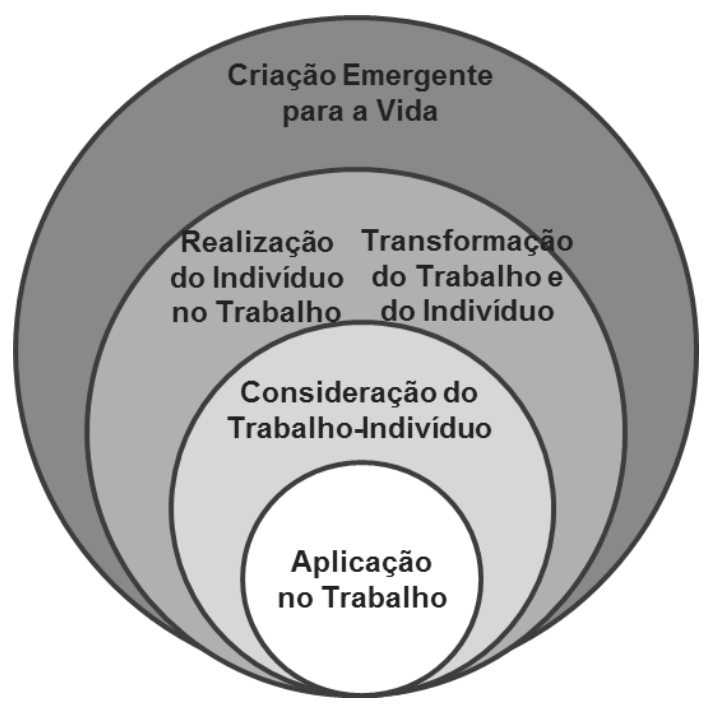

C

Figura 1. Mapa do Espaço de Resultado para as Concepções acerca da Valoração do Conhecimento no Contexto do Trabalho

O modelo A da Figura 1 ilustra o Mapa do espaço de resultado conforme preconizado pelos autores do método fenomenográfico, com setas unidirecionais. O modelo B da Figura 1 apresenta o Mapa do espaço de resultado de acordo com os achados fortuitos relatados pelos autores do presente estudo, com setas bidirecionais. E o modelo C representa o Mapa do espaço de resultado, conforme proposto pelos participantes do grupo de foco. Fonte: Elaborada pelos autores do estudo e pelos participantes do grupo de foco, no último caso. 


\section{Achados Fortuitos Emergentes Relacionados ao Método Fenomenográfico}

Além das concepções emergentes, o estudo encontrou achados fortuitos relacionados ao método fenomenográfico, que foram discutidos e validados no grupo de foco com participantes prototípicos das categorias descritas.

\section{Movimento bidirecional dos sujeitos pelas concepções do fenômeno}

O primeiro achado diz respeito ao movimento bidirecional dos sujeitos pelas concepções do fenômeno. Conforme inferido na literatura do método fenomenográfico (Bowden \& Green, 2005; Marton, 1981; Marton \& Booth, 1997; Sandberg, 2001), os indivíduos caminham hierarquia acima na estrutura do mapa do espaço de resultado no sentido unidirecional de ampliação de sua consciência focal à medida que vivenciam repetidas vezes o fenômeno. Na pesquisa ora ilustrada, diferentemente, encontraram-se sujeitos que fizeram o movimento inverso, voltando atrás em sua concepção, apesar de terem expandido sua consciência focal.

No estudo realizado, o método pareceu revelar o livre movimento bidirecional dos sujeitos ao experimentar o fenômeno, assim como ao não se sentir confortável com determinada concepção predominante em um local de trabalho. Tal achado se deu com os entrevistados 3, 6, 7, 10 e 20, em suas narrativas de trajetória de carreira e motivações para sair de determinada organização, relacionadas à não valoração de sua concepção de conhecimento, no que diz respeito às categorias descritivas que percorreram no sentido ascendente e descendente no mapa do espaço de resultados.

Um exemplo de retroceder na hierarquia do mapa do espaço de resultado foi o da entrevistada 10. A empresa onde ela se encontrava passou por uma fusão e a entrevistada começou a experimentar uma nova concepção de valoração do conhecimento relacionada à Transformação do Indivíduo e do Trabalho. Ela conseguiu discernir essa nova concepção e, ao vivenciá-la, decidiu pedir demissão da empresa a fim de seguir para outra organização onde procurava retornar à concepção com a qual se sentia mais confortável, da Realização do Indivíduo no Trabalho.

Já no caso do entrevistado 3, o profissional relatou sua curta passagem por uma empresa multinacional de origem nórdica, em que as decisões eram muito discutidas entre os pares e gestores na busca de consenso, tornando a tomada de decisão mais lenta, porém mais sólida e com conhecimento compartilhado. Ao começar a trabalhar nessa empresa, o entrevistado experimentou a concepção da Realização do Indivíduo no Trabalho e, também, sua não adaptação a essa concepção ("meu conhecimento não era aproveitado, tudo era discutido, muito discutido"). Ele retornou a uma organização em que a concepção de conhecimento valorado voltava a ser direcionada para Aplicação no Trabalho e medida por resultado (concepção mais estreita).

Quatro participantes do grupo de foco reconheceram situações na carreira em que já haviam estado em uma concepção e decidiram mudar de organização, recuando para uma concepção anterior (hierarquia descendente do mapa do espaço de resultado) e/ou movendo-se para a busca de uma concepção mais alinhada com suas crenças, valores e personalidade, a fim de ter algum "conforto" no trabalho. Essa constatação sugere que o mapa do espaço de resultado deveria ser representado com setas bidirecionais, conforme proposto no modelo B da Figura 1. A entrevista em grupo validou que não necessariamente os sujeitos caminham apenas hierarquia acima em suas concepções à medida que experimentam o fenômeno; os sujeitos são livres e podem preferir ficar com um tipo de concepção e repeti-la no decorrer da carreira, mesmo tendo experimentado novos elementos e concepções do fenômeno.

\section{Continuum ininterrupto entre concepções}

O segundo achado refere-se ao continuum ininterrupto entre concepções. Não é objetivo da fenomenografia abrir um grande número de categorias descritivas pouco inclusivas, mas de concentrar 
os achados em um número adequado de categorias descritivas relevantes que ajudem a compreender o fenômeno como um todo articulado (Bowden \& Green, 2005; Marton, 1981; Sandberg, 2000). Entretanto, o emprego do método na pesquisa revelou sujeitos em trânsito, movendo-se no meio do caminho entre categorias. Nessa situação, os indivíduos apresentavam uma concepção composta por dimensões referentes a uma categoria, ao mesmo tempo em que começavam a divisar e se questionar acerca de alguns aspectos - seja de percepção, pensamento ou ação - relacionados à categoria seguinte do espaço de resultado. Entretanto, tal posição intermediária não constituía uma conceituação forte o suficiente para justificar a abertura de uma nova categoria descritiva. O método pareceu revelar um filme em fluxo, o continuum ininterrupto entre concepções, e não uma foto de momento, estanque, em que a categoria classifica, rotula e aprisiona o sujeito. Tal achado se deu com os entrevistados 12, 14, 16, 20 e 22, quando da análise de suas narrativas na tentativa de classificá-los em uma concepção.

Um exemplo de trânsito entre duas concepções deu-se com a entrevistada 22. Ela possuía um histórico de 14 anos em uma organização, onde havia ingressado como secretária e tinha percorrido uma trajetória de carreira até a recente promoção à Coordenação de $\mathrm{RH}$, abaixo apenas da Diretora de RH, após ter sido preterida uma vez para essa posição. A entrevistada possuía a concepção da Aplicação no Trabalho, em que o conhecimento valorado tratava-se daquele responsável por resultados efetivos; concepção útil para o bom andamento do ambiente organizacional e representada pela aplicação do conhecimento da própria organização, possuindo rotinas organizacionais muito estruturadas e definidas, das quais a entrevistada é guardiã após tantos anos de trabalho no mesmo lugar. Entretanto, em vários momentos da narrativa, a entrevistada transita pelo reconhecimento e pela consideração conferidos a ela por razão do conhecimento que detém dos processos e rotinas organizacionais; fala sobre a confiança da liderança e chefias ao considerarem o conhecimento dela, que se concretizou com a promoção de cargo. Estes são aspectos inerentes à concepção da Consideração do Trabalho-Indivíduo.

Outro exemplo ilustrativo é o do entrevistado 14. Depois de repetidas experiências similares na concepção da Transformação do Trabalho e do Indivíduo, ele começou a vislumbrar aspectos da concepção seguinte, da Criação Emergente para a Vida. Em seus questionamentos, demonstrava começar a conceber que seus conhecimentos de valor, aqueles que poderiam transformar a organização, não necessariamente seriam aqueles que a organização onde se encontrava desejava. Assim, questionava-se se estaria disposto a empenhar novo risco pessoal e profissional naquela ação. Ele evidenciava discernir novos elementos em sua consciência focal com relação ao fenômeno.

Para o fenômeno da valoração do conhecimento, o método fenomenográfico capturou em certos entrevistados o momento de ampliação da consciência focal, de mudança de uma concepção a outra. Desse modo, embora os entrevistados possuíssem uma concepção acerca do fenômeno, transitavam pela categoria seguinte durante vários momentos de suas narrativas, como se não houvesse uma fronteira de demarcação entre as concepções. Tal aspecto só pôde ser percebido porque a fenomenografia possui a característica de inter-relacionar, de buscar a interdependência entre as categorias descritivas, umas com as outras, de modo tangível e concreto no espaço de resultado.

\section{Trajetória dinâmica e flexível dos indivíduos pelas concepções no tempo e espaço: concepções como modos de ação}

O terceiro achado revela a trajetória dinâmica e flexível dos indivíduos pelas concepções do fenômeno no tempo e espaço. No momento da análise, o encadeamento lógico e inclusivo entre as categorias descritivas apresentou-se bastante evidente na leitura da trajetória de carreira dos indivíduos à luz das categorias descritivas emergentes das narrativas (concepções). Pôde-se perceber com clareza os movimentos feitos pelos sujeitos em suas concepções acerca da valoração do conhecimento durante sua vida profissional (trânsito pelo mapa do espaço de resultado). Entretanto, para além desse aspecto, foi possível observar uma trajetória dos sujeitos pelas concepções (até o limite de sua consciência focal) de modo dinâmico e flexível, relacionando o momento profissional, organizacional e pessoal (contexto sócio-espaço-temporal) com a concepção utilizada. As concepções assemelhavam-se a modos de ação utilizados pelos sujeitos em suas atividades, e não se portavam como categorias descritivas estáticas que rotulam e estabelecem os comportamentos dos sujeitos. 
Investigar tal achado no grupo de foco trouxe revelações instigantes acerca do uso das concepções e do espaço de resultado fenomenográfico para o fenômeno da valoração do conhecimento. Os participantes expressaram que se sentem inseridos em diferentes categorias ao mesmo tempo, dependendo das diferentes situações (grupos e contextos) a que são submetidos no trabalho. Eles analisaram que, por um lado, tratava-se do fato de as concepções serem inclusivas e, assim, estarem presentes simultaneamente no indivíduo, onde cada uma delas parecia se acentuar em diferentes situações. Por outro lado, o trânsito de uma a outra categoria, hierarquia acima, também gerava essa percepção, na qual o indivíduo ganha mais consciência focal na medida em que é exposto repetidas vezes ao fenômeno.

Os integrantes do grupo de foco expressaram que o fato de assumir uma concepção de conhecimento de valor e comportamentos (ação) relacionados está intimamente ligado ao contexto sócio-espaço-temporal no qual o indivíduo se encontra: não apenas contextos profissionais e organizacionais, mas também pessoais (momentos de vida). Concordaram fortemente com a inferência proposta pelo método de que as concepções mudam durante a trajetória da vida e da carreira. Entretanto, os participantes informaram que essas mudanças são mais intensamente dirigidas pelo ambiente/contexto organizacional e pela necessidade de nele se encaixar.

Afirmaram, também, encontrar várias concepções distintas coexistindo na organização, ou seja, percebem diferentes indivíduos e grupos que pensavam de modo similar às diferentes concepções apresentadas, convivendo na mesma organização. Sugere-se que as diferentes concepções coexistem, pois os grupos sociais na organização percebem o contexto e constroem, juntos, uma visão de como devem utilizar seus conhecimentos de valor no trabalho, a partir de uma percepção do que a organização valoriza. Por causa disso, os sujeitos expressaram e demonstraram se utilizar das concepções de forma ainda mais fluida, transitória e dinâmica do que o encontrado na própria análise das narrativas da pesquisa: relataram que mudam de concepção, e agem em acordo a ela, diante de diferentes grupos e situações no mesmo ambiente de trabalho, ao longo do mesmo dia. Essas mudanças de concepção, até o limite da consciência focal do indivíduo, ocorriam, por exemplo, ao lidar com diferentes áreas e departamentos da empresa, que possuem características diversas, ou ao participar de um projeto novo, quando são exigidas diferentes concepções de conhecimento de valor.

A fenomenografia pareceu exibir uma visão tridimensional do fenômeno, em que os indivíduos fluem pelas concepções do quadro bidimensional do espaço de resultado, até o limite de sua consciência acerca do fenômeno, associada ao uso dinâmico das concepções como modos de ação em vários momentos e situações diárias (tempo e espaço).

Ao final, os participantes do grupo de foco validaram o mapa do espaço de resultado em suas concepções inclusivas, hierárquicas e bidirecionais. Entretanto, ficaram muito incomodados com a figura na forma de organograma, e sugeriram que um caminho fluido e contínuo, que permitisse o trânsito de uma a outra categoria, devesse ser representado de outro modo. A imagem dos círculos inclusivos das categorias descritivas pareceu representar melhor, para eles, o mapa do espaço de resultado. Tal representação e contribuição proposta pelos participantes se encontra no modelo $\mathrm{C}$ da Figura 1. Nela, o mapa do espaço de resultado é visto como um continuum ininterrupto e inclusivo quando comparado ao mapa do espaço de resultado proposto pelos autores do método (modelo A da Figura 1) e autores da pesquisa (modelo B da Figura 1). 


\section{Conclusão: Diálogo entre o Método Fenomenográfico e o Fenômeno da Valoração do Conhecimento}

Este artigo conceitual objetivou revelar a experiência de pesquisa com o emprego da fenomenografia, explicitando os achados fortuitos relacionados ao método. Entre esses achados, desvelou-se que o método pôde capturar: (a) a dinamicidade do movimento bidirecional dos indivíduos por suas concepções do fenômeno ao experimentá-lo de formas diversas; (b) o continuum ininterrupto entre as concepções, que modificaria a forma de representar o mapa do espaço de resultado de caminho hierárquico a círculos de concepções inclusivos; e (c) a trajetória dinâmica e flexível dos indivíduos pelas concepções do fenômeno - até o limite de sua consciência focal - no tempo e espaço, utilizandoas como modos de ação para guiar seus comportamentos diante de diversos grupos e situações.

Cabe colocar em questão se os achados emergentes relacionados à fenomenografia dizem respeito às características intrínsecas ao método fenomenográfico ou se são aspectos relativos ao fenômeno estudado - da valoração do conhecimento no contexto do trabalho. Propôs-se, no presente artigo, que se tratam de propriedades inerentes ao método fenomenográfico, advindas do seu modo de: explorar e compreender o fenômeno de forma integral; inter-relacionar as categorias descritivas a fim de gerar um todo inclusivo, interdependente e articulado; e posicionar os indivíduos como parte consciente de aspectos da realidade, ao mesmo tempo em que são integrantes e constituintes da mente coletiva que concebe uma realidade. Sugere-se, assim, que o mapa do espaço de resultado oriundo da pesquisa fenomenográfica revela um filme vivo, e que as categorias descritivas que o compõem não rotulam ou aprisionam os sujeitos em padrões estáticos.

A confirmação desses achados acerca da fenomenografia só se tornou viável pelo uso da triangulação dos dados (Denzin, 1978; Denzin \& Lincoln, 2000) durante a execução do estudo, possível na corrente da fenomenografia pura, de Marton (1981). A combinação da realização do método de entrevista em grupo (Goldman \& McDonald, 1987) com participantes prototípicos revelados na pesquisa fenomenográfica pura permitiu a verificação, a validação e, especialmente, o aprofundamento da compreensão dos achados relacionados à fenomenografia.

Quanto à fenomenografia, vale ressaltar que a experiência e o emprego deste método em estudos organizacionais ainda são restritos. É possível afirmar que há desconhecimento acerca do método, que se propagou com mais facilidade nas Áreas da Educação e das Ciências da Saúde. Dessa forma, vale ressaltar a adequação e os benefícios do uso do método à questão da prática nas organizações. O método fenomenográfico possui a característica de conceber a questão de estudo a partir da prática e a pesquisa se desenrola pela experiência vivida dos sujeitos, na perspectiva deles. Ao realçar como os sujeitos concebem determinados fenômenos organizacionais contextuais, a fenomenografia fornece resultados para uma ação prática gerencial sobre os indivíduos e a organização, na direção de uma concepção comum almejada (Chen \& Partington, 2006; Chen, Partington, \& Wang, 2008; Dall'Alba \& Sandberg, 1996; Partington, Pellegrinelli, \& Young, 2005; Partington \& Young, 2002; Pellegrinelli, Partington, \& Young, 2003; Sandberg, 1991, 2000, 2001, 2009).

Para fins de pesquisa científica acadêmica, como benefícios, o método fenomenográfico captura, a um só tempo, o amplo espectro e o profundo entendimento do fenômeno, por meio das diferentes concepções interligadas descritas em termos de várias dimensões do fenômeno (Akerlind, 2005a; Bowden \& Green, 2005), possibilitando reconceituar o fenômeno estudado a partir de uma nova perspectiva (Sandberg, 1991, 2000, 2001, 2009) e/ou criar uma base sólida para uma linha de estudos (Akerlind, 2005a). A estrutura resultante no mapa e espaço de resultado apresenta um cenário palpável para o estudo continuado de temas complexos, emergentes ou pouco estudados. Contudo, cabe ressaltar as limitações do emprego da fenomenografia, como a dificuldade em manipular simultaneamente uma grande massa de dados e, sobretudo, articular um pensamento sintético acerca da inter-relação das concepções antes de proceder ao tratamento analítico dos dados. Esse aspecto implica a restrição a uma ou duas perguntas centrais por projeto de pesquisa, dado o tempo de tratamento e análise dos dados até chegar às categorias descritivas finais (Akerlind, 2005a). 
O presente artigo conceitual ateve-se à observação do uso prático da fenomenografia em uma pesquisa empírica e de seu emprego, por terceiros, em dois estudos adicionais, o que confere uma limitação aos achados aqui expostos. Sugere-se, portanto, um estudo de meta-análise com pesquisadores que se utilizaram da fenomenografia, a fim de corroborar tais achados ou propor novos aspectos decorrentes da experiência com o método. De todo modo, a disseminação da fenomenografia adicionará uma rica opção para os pesquisadores interessados em métodos qualitativos.

\section{Referências}

Akerlind, G. S. (2005a). Learning about phenomenography: interviewing, data analysis and the qualitative research paradigm. In J. Bowden \& P. Green (Orgs.), Doing developmental phenomenography (pp. 63-73, Qualitative Research Methods Series). Melbourne: RMIT University Press.

Akerlind, G. S. (2005b). Phenomenographic methods: a case illustration. In J. Bowden \& P. Green (Orgs.), Doing developmental phenomenography (pp. 103-127, Qualitative Research Methods Series). Melbourne: RMIT University Press.

Bardin, L. (1979). Análise de conteúdo. Lisboa: Edições 70.

Bowden, J. (2005). Reflections on the phenomenographic team research process. In J. Bowden \& P. Green (Orgs.), Doing developmental phenomenography (pp. 11-31, Qualitative Research Methods Series). Melbourne: RMIT Press.

Bowden, J., \& Green, P. (2005). Doing developmental phenomenography (Qualitative Research Methods Series). Melbourne: RMIT Press.

Bowden, J., \& Walsh, E. (2000) Phenomenography (Qualitative Research Methods Series). Melbourne: RMIT University Press.

Brown, G., \& Yule, G. (1988). Discourse analysis. Cambridge University Press.

Brown, J. S., \& Duguid, P. (1991). Organizational learning and communities-of-practice: toward a unified view of working, learning, and innovation. Organization Science, 2(1), 40-57. http://dx.doi.org/10.1287/orsc.2.1.40

Bryant, A., \& Charmaz, K. (2007). The Sage handbook of grounded theory. Thousand Oaks: Sage.

Chen, P., \& Partington, D. (2006). Three conceptual levels of construction project management work. International Journal of Project Management, 24(4), 412-421. http://dx.doi.org/ 10.1016/j.ijproman.2006.02.009

Chen, P., Partington, D., \& Wang, J. N. (2008). Conceptual determinants of construction project management competence: a Chinese perspective. International Journal of Project Management, 26(6), 655-664. http://dx.doi.org/10.1016/j.ijproman.2007.09.002

Collier-Reed, B., \& Ingerman, Å. (2013). Phenomenography: from critical aspects to knowledge claim. International Perspectives on Higher Education Research, 9, 243-260. http://dx.doi.org/10.1108/S1479-3628(2013)0000009016

Corbin, J. M., \& Strauss, A. (1990). Grounded theory research: procedures, canons, and evaluative criteria. Qualitative Sociology, 13(1), 3-21. http://dx.doi.org/10.1007/BF00988593

Dall'alba, G., \& Hasselgren, B. (1996). Reflections on phenomenography: toward a methodology? Göteborg: Acta Universitatis Gothorburgensis. 
Dall'alba, G., \& Sandberg, J. (1996). Educating for competence in professional practice. Instructional Science, 24(4), 411-437. http://dx.doi.org/10.1007/BF00125578

Denzin, N. (1978). The research act: a theoretical introduction to sociological methods (2nd ed). New York: Mc Graw-Hill.

Denzin, N., \& Lincoln, Y. (2000). Handbook of qualitative research. Thousand Oaks: Sage.

Entwistle, N. (Ed.). (1997). Phenomenography in higher education (special issue). Journal of the Higher Education Research and Development Society of Australasia HERDSA, 16(2), 125-252. http://dx.doi.org/10.1080/0729436970160202

Gherardi, S. (2000). Practice-based theorizing on learning and knowing in organizations. Organization, 7(2), 211-223. http://dx.doi.org/10.1177/135050840072001

Gibbings, P. D. (2008). Experience of problem-based learning in virtual space: a phenomenographical study (Doctoral thesis). Queensland University of Technology Faculty of Education, Brisbane, Queensland, Australia.

Glaser, B. G., \& Strauss, A. L. (2006). The discovery of grounded theory: strategies for qualitative research. New Brunswick: Aldine Transaction.

Goldman, A. E., \& McDonald, S. S. (1987). The group depth interview: principles and practice. Englewood Cliffs: Prentice-Hall.

Hasselgren, B., \& Beach, D. (1997). Phenomenography-a "good-for-nothing brother" of phenomenology? Outline of an analysis. Higher Education Research \& Development, 16(2), 191202. http://dx.doi.org/10.1080/0729436970160206

Latour, B. (2012). Reagregando o social: uma introdução à teoria do ator-rede. Salvador: EDUFBA/EDUSC.

Lave, J., \& Wenger, E. (1991). Situated learning: legitimate peripheral participation. Cambridge: Cambridge University Press.

Marton, F. (1981). Phenomenography - describing conceptions of the world around us. Instructional Science, 10(2), 177-200. http://dx.doi.org/10.1007/BF00132516

Marton, F. (1986). Phenomenography — a research approach to investigating different understandings of reality. Journal of Thought, 21(3), 28-49. Recuperado de http://www.jstor.org/stable/42589189

Marton, F., \& Booth, S. A. (1997). Learning and awereness. Mahwah: Lawrence Erlbaum Inc. Publishers.

Marton, F., \& Säljö, R. (1976). On qualitative differences in learning II: outcome as a function of the learner's conception of the task. British Journal of Educational Psychology, 46(2), 115-127. http://dx.doi.org/10.1111/j.2044-8279.1976.tb02304.x

Moustakas, C. (1994). Phenomenological research methods. Thousand Oaks: Sage.

Orlikowski, W. J. (2002). Knowing in practice: enacting a collective capability in distributed organizing. Organization Science, 13(3), 249-273. http://dx.doi.org/10.1287/orsc.13.3.249.2776

Patriotta, G. (2003). Organizational knowledge in the making: how firms create, use, and institutionalize knowledge. New York: Oxford University Press.

Partington, D., \& Young, M. (2002, August). Configuring knowledge in practice-grounded research networks: a contemporary example. Proceedings of the Academy of Management Annual Meeting, Denver, CO, EUA, 62. 
Partington, D., Pellegrinelli, S., \& Young, M. (2005). Attributes and levels of programme management competence: an interpretative study. International Journal of Project Management, 23(2), 87172. http://dx.doi.org/10.1016/j.ijproman.2004.06.004

Pellegrinelli, S., Partington, D., \& Young, M. (2003, May). Understanding and assessing programme management competence. Proceedings of the PMI's Global Congress 2003-Europe, The Hague, The Netherlands.

Richardson, J. T. E. (1999). The concepts and methods of phenomenographic research. Review of Educational Research, 69(1), 53-68. http://dx.doi.org/10.3102/00346543069001053

Säljö, R. (1979). Learning about learning. Higher Education, 8(4), 443-451. http://dx.doi.org/10.1007/BF01680533

Sandberg, J. (1991). Competence as intentional achievement: a phenomenographic study. [Occasional Paper 91.4]. ERADU Educational Research and Development Unit, Melbourne: RMIT.

Sandberg, J. (2000). Understanding human competence at work: an interpretative approach. Academy of Management Journal, 43(1), 9-25. http://dx.doi.org/10.2307/1556383

Sandberg, J. (2001). Understanding the basis for competence development. International Perspectives on Competence in the Workplace, 9-25. http://dx.doi.org/10.1007/978-94-010-0742-9_2

Sandberg, J. (2009). Understanding of work: the basis for competence development. International Perspectives on Competence in the Workplace, 3-20. http://dx.doi.org/10.1007/978-1-4020-87547_1

Swart, J. (2011). That's why it matters: how knowing creates value. Management Learning, 42(3), 319332. http://dx.doi.org/10.1177/1350507610391591

Webb, G. (1997). Deconstructing deep and surface: towards a critique of phenomenography. Higher Education, 33(1), 195-212. http://dx.doi.org/10.1023/A:1002905027633

\section{Dados dos Autores}

Andréa Cherman

Rua Marques de São Vicente, 225, Gávea, 22451-900, Rio de Janeiro, RJ, Brasil. E-mail: acherman@ @rof.iag.puc-rio.br

Sandra Regina Rocha-Pinto

Rua Marques de São Vicente, 225, Gávea, 22451-900, Rio de Janeiro, RJ, Brasil. E-mail: sanpin@iag.puc-rio.br 